\title{
DETEKSI DINI KANKER SERVIKS DENGAN PEMERIKSAAN SERVIKS DI KELURAHAN BULURAN KENALI KOTA JAMBI TAHUN 2017
}

\author{
Julaecha $^{1)}$, Nurfitriani' ${ }^{2}$ \\ ${ }^{1}$ Prodi D III Kebidanan STIKes Baiturrahim Jambi \\ ${ }^{2}$ Prodi D III Keperawatan STIKes Baiturrahim Jambi \\ Email: echa_mamee@yahoo.com
}

\begin{abstract}
Cervical cancer is a malignant disease that occurs in the cervik. Course of the disease is preceded by the condition of pre-concerous lesions of the cerviks is the existence of dysplasi/cervical intraepithelial neoplasia (NIS). On each day is expeced to 40-45 new cases and about 20-25 people die from cervical cancer. Based on those considered very necessary to provide education on cervical cancer in women of reproductive age in the prevention of cervical cancer prevention effort.Target outcomes expected are: there is an increased knowledge an increase in knowledge between before and after extension and capable of early detection of cancer serviks increase. Implementation method to provide counseling.The results showed that there was important of mother's interest in doing pap smears examination before and after counseling.
\end{abstract}

Keywords: Counseling, cervical cancer, pap smears

\begin{abstract}
ABSTRAK
Kanker serviks merupakan penyakit keganasan yang terjadi pada leher rahim. Perjalanan penyakit ini diawali dengan kondisi lesi pra kanker di leher rahim yaitu adanya displasia/neoplasia intraepitel servik(NIS). Pada tiap harinya diperkirakan muncul 40-45 kasus baru dan sekitar 20-25 orang meninggal akibat kanker serviks .Berdasarkan hal tersebut dipandang sangat perlu memberikan penyuluhan tentang kanker serviks dengan pemeriksaan pap smear pada wanita usia subur dalam upaya peningkatan pencegahan kanker serviks. Target luaran yang diharapakan antara lain terjadi peningkatan pengetahuan antara sebelum dan sesudah penyuluhan, kesadaran ibu untuk melakukan deteksi dini kanker serviksdan mengintegrasikan materi deteksi dini kanker serviks dengan pemeriksaan pap smear kedalam mata kuliah askeb keluarga berencana dan kesehatan reproduksi.Metode pelaksanaan dengan memberikan penyuluhan.Hasil. setelah dilakukan penyuluhan ada peningkatan pengetahuan dan minat ibu untuk melakukan pemeriksaan pap smear.
\end{abstract}

Kata Kunci: Penyuluhan, kanker servik, pap smear

\section{PENDAHULUAN}

Penyakit kanker merupakan salah satu penyebab kematian utama di seluruh dunia, antara lain karena kanker payudara dan serviks.Berdasarkan data Globacon, International Agency For Research on Cancer (IARC) diketahuibahwa pada tahun 
2012 terdapat 14.067.894 kasus baru kanker dan8.201.575 kematian akibat kanker diseluruh dunia. Hampir sembilan dari sepuluh(87\%) kematian akibat kanker serviks terjadi di daerah tertinggal. (Globocon, 2012).

Indonesia merupakan salahsatu negara dengan angka penderita kanker yang tinggi. Data Kementerian Kesehatan menunjukkan, tahun 2015rata-rata setiap jam jumlah penderita kanker leher rahim atau serviks bertambah 2,5 orang dan korban meninggal 1,1.Angka ini di prediksikan akan terus meningkat $25 \%$ dalam kurun waktu 10 tahun mendatang jika tidak segera dilakukan pencegahan (Rasjidi, 2012: 6)

Faktor risiko terjadinya kanker serviksadalah hubungan seksual pertama kali dibawah usia 18 tahun, karena karsinoma serviks diperkirakan sebagai penyakit yang ditularkan secara seksual, di mana beberapa bukti menunjukkan adanya hubungan antara riwayat hubungan seksual dengan penyakit ini. Sesuai dengan penyebab infeksinya wanita dengan pasangan seksual yang banyak dan memulai hubungan seksual pada usia muda kurang dari 18 tahun akan meningkatkan risiko kanker serviks lima kali lipat (Maharani, 2008:81)

Kejadian kanker serviks membutuhkan proses yang dimulai dari infeksi HPV sampai menjadi kanker. Oleh karena itu skrining secara rutin diperlukan untuk mendeteksi secara dini kanker serviks. Kanker serviks termasuk penyakit yang dapat dicegah karena mempunyai fase prakanker yang cukup panjang.

Dewasa ini sudah dikenal beberapa metode deteksi dini kanker serviks yaitu tes pap smear, IVA. Namun yang sesuai dengan kondisi di negara berkembang termasuk Indonesia adalah dengan menggunakan metode IVA dan pap smear, karena tekniknya mudah dan sederhana, biayanya murah, tingkat sensitifitasnya tinggi, cepat serta cukup akurat untuk menemukan kelainan pada tahap kelainan sel (Displasia) atau sebelum pra kanker. Namun, kurangnya kesadaran dari wanita usia subur untuk melakukan deteksi dini kanker serviks menjadikan pemeriksaan IVA dan pap smear ini kurang diminati (Fauziah, 2011: 448)

Kesadaran masyarakat untuk memeriksakan diri sejak dini dirasakan sangat rendah., selain itu masyarakat merasa pemeriksaan pap semar dianggap tabu, ibu merasa malu untuk melakukan pemeriksaan pemeriksaan. $70 \%$ penderita kanker serviks yang datang ke Rumah Sakit sudah pada stadium lanjut. Hal ini didukung oleh penelitian Sumartini (2013), rendahnya cakupan deteksi dini merupakan salah satu alasan makin berkembangnya kanker serviks. Hal ini berdasarkan fakta lebih dari $50 \%$ perempuan yang terdiagnosis kanker tidak pernah menjalani deteksi dini sebelumnya, dari 6,7 penelitian di Rumah Sakit Cipto Mangunkusumo menunjukkan sekitar $69,4 \%$ dari perempuan yang terdiagnosis kanker tidak pernah menjalani deteksi dini. Dalam penelitian ini pendidikan dan pengetahuan berpengaruh terhadap niat perempuan untuk melaksanakan deteksi dini kanker serviks (Sumartini, 2013: 2).

Menurut Rokhmawati (2011) bahwa perilaku masih menjadi penghambat pada wanita usia subur untuk melakukan deteksi dini kanker leher rahim. Proses pembentukan atau perubahan perilaku dapat dipengaruhi oleh beberapa faktor baik dari dalam diri individu maupun luar individu. Sikap seseorang dapat berubah dengan diperolehnya tambahan informasi dari 
kelompok sosialnya. Kelompok sosial yang dimaksud adalah dukungan dari suami, keluarga, teman dan petugas kesehatan.Kondisi ini mengakibatkan angka kejadian kanker serviks di Indonesia masih cukup tinggi karena cakupan deteksi dini yang masih sangat rendah sehingga perlu dilakukan upaya-upaya untuk meningkatkan pengetahuan wanita usia subur tentang pentingnya deteksi dini kanker servik secara rutin.(I Gede Putu Darma S. 2017).

Berdasarkan uraian diatas sangat perlu memberikan penyuluhan tentang deteksi dini kankerservikspada wanita usia subur upaya preventif pencegahan kanker serviks. Target luaran yang diharapkan adalah. Terjadi peningkatan pengetahuan dan kesadaran untuk melakukan pemeriksaan pap smear. Metode pelaksanaan dengan memberikan penyuluhan.(Ni Made Nurtini. 2017)

Buluran Kenali merupakan kelurahan yang berada di Telanaipura. Tujuan pengabdian kepada masyarakat ini adalah memanfaatkan pelayann kesehatan dengan maksimal atas dasar kesadaran dan kepedulian serta partisipasi serta kewaspadaan warga.

\section{TARGET DAN LUARAN}

Target diharapkan adalah wanita usia subur yangsudah melakukan hubungan seksual secara teratur setiap tahun melakukan deteksi dini dengan pemeiksaan pap smear agar terdeteksi secara dini lesi pra kanker/kanker. Salah satu program pemerintah yang digalang adalah meningkatkan pelaksanaan pencegahan dan deteksi dini kanker pada perempuan di Indonesia mulai tahun 2015 - 2019. Adapun luaran dari pengabdian kepada masyarakat ini adalah mengintegrasikan materi deteksi dini kanker serviks dengan mata kuliah askeb keluarga berencana dan kesehatan reproduksi.

\section{METODE PELAKSANAAN}

Pelaksanaan kegiatan penyuluhan deteksi dini kanker serviks dengan pemeriksaan pap smear di RT 15 Kelurahan Buluran Kenali, Telanaipura Kota Jambi pada bulan April-Mei 2017 sebaga implementasi dari Tri darma Perguruan Tinggi. Metode pendekatan yang dilakukan melalui pemberian penyuluhan bagi ibu-ibu kader kesehatan dan kelompok masyarakat (pengajian). Populasi pada kegiatan ini adalah seluruh ibu-ibu pengajian yang berada di RT 15 Buluran Kenali, sampel sebanyak 35 orang yang hadir pada saat penyuluhan. Kegiatan pendukung yang dilakukan antara lain: Melakukan program bersama mitra, penjadwalan kegiatan (waktu, tempat, tenaga dan biaya), beberapa tahapan partisipasi mitra dalam pelaksanaan program penyuluhan deteksi dini kanker serviks dengan pemeriksaan pap smear. Penyebaran undangan pelaksanaan kegiatan penyuluhan,Melakukan analisa,tindak lanjut dan evaluasi kegiatan.

\section{HASIL DAN PEMBAHASAN}

Hasil dari penyuluhan pada ibu-ibu majlis ta'lim bahwa sebagian dari mereka baru mengethaui tentang pemeriksaan pap smear an tempat pemeriksaan serta mampu menjelaskan tentang deteksi kanker serviks, Setelah dilakukan penyuluhan 25 dari 35 orang peserta yang hadir akan melakukan pemeriksaan pap smear dan bersedia kontrol rutin setiap tahun dan mau mengajak ibu yang lainnya untuk pap smear.

Setelah dilakukan penyuluhan banyak peserta penyuluhan yang bertanya tentang tanda-tanda kanker serviks, syarat melakukan pemeriksaan pap semar dan cara mencegah kanker serviks, tempat 
pemeriksan dan biaya pemeriksaan. Dapat dikatakan bahwa belum semua wanita usia subur mengetahui tentang pentingnya pemeriksaan pap smear dan dimana tempat pemeriksaan.

Kepada ibu-ibu yang belum melakukan pemeriksaan harap segera melakukan pemeriksaan rutin dan ibu yang telah melakukan pemeriksaan secara kontinyu atau setiap tahun untuk melakukan pemeriksaan pap smear. Kepada para suami, maupun masyarakat dewasa yang telah aktif melakukan atau pernah melakukan kontak seksual agar mendukung istri/ keluarga perempuan untuk pemeriksaan pap smear secara rutin.

Sesuai dengan teori dengan adanya penyuluhan sikap ibu dalam melakukan pemeriksaan pap smear meningkat karena pada saat penyuluhan inilah terjadi transfer ilmu pengetahuan dan wawasan tentang pemeriksaan pap smear. Media yang digunakan pada saat penyuluhan berupa leafleat berwarna dengan ilustrasi gambar mulut rahim mendekati warna aslinya diberikan ke peserta penyuluhan dan ibu ketua arisan agar dapat disosialisasikan pada ibu-ibu, khususnya di kelurah Buluran Kenali. Memudahkan ibu-ibu untuk memahami pentingnya deteksi dini kanker dan seputar tentang kanker serviks.

Kegiatan ini hanya di follow up saat pelaksanaan karena bersifat skrining atau penapisan awal kanker leherleher rahim dengan prosentase yang tinggi. rahim sehingga diharapkan dapat membantu program pemerintah

Hasil ini sejalan dengan penelitian Anita Dewi di Sleman tahun 2013 terdapat pengaruh penyuluhan tentang kanker serviks dengan metode peer group terhadap minat ibu untuk melakukan pap smear di desa caturharjo sleman. Didukung oleh penelitian Warni tentang Keefektifan Promosi Kesehatan Terhadap Pengetahuan, Sikap dan Perilaku Tentang Tes IVA pada Wanita Usia 20-59 menunjukkan terdapat perbedaan yang bermakna antara pengetahuan, sikap dan perilaku sebelum dan sesudah diberi promosi kesehatan dengan leaflet dan dengan motivasi oleh tokoh masyarakat tentang deteksi dini kanker serviks dengan peeriksaan IVA tes. (Warni. 2017)

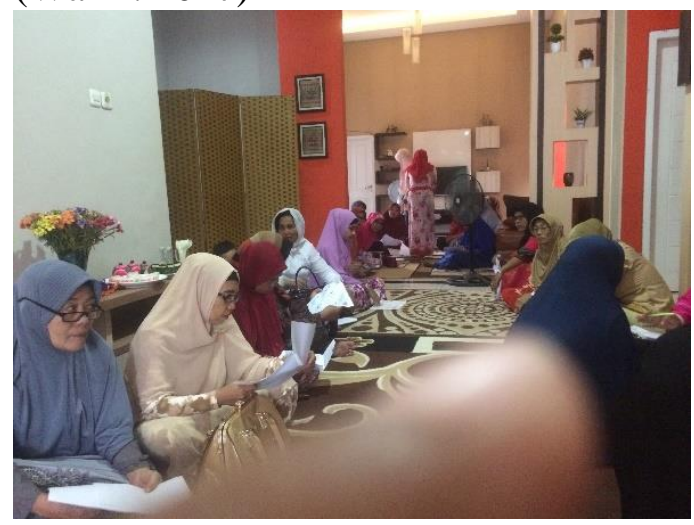

Gambar.1 Kegiatan pengabdian

\section{KESIMPULAN DAN SARAN}

\section{Kesimpulan}

Penyuluhan tentang deteksi dni kanker serviks yang telah diselenggarakan mampu meningkatkan pengetahuan dan kesadaran wanita usia subur tenang kanker serviks dan menyadari pentingnya deteksi dini. Luaran yang dicapai adalah mengintegrasikan materi deteksi dini kanker serviks dengan mata kuliah asuhan kebidanan keluarga berencana dan kesehatahatan reproduksi agar mahasiswa dapat melakuakan deteksi dini kanker servik di masyarakat nantinya.

\section{Saran}

Disarankan kepada ibu-ibu yang belum melakukan pemeriksaan agar segera melakukan pemeriksaan rutin dan ibu yang telah melakukan pemeriksaan, hendaknya secara kontinyu untuk melakukan pemeriksaan pap smear. 


\section{UCAPAN TERIMA KASIH}

Terima kasih kami ucapkan kepada Ketua STIKes Baiturrahim Jambi atas bantuan dana pengabdian kepada masyrakat ini, terima kasih juga kami sampaikan kepada semua pihak yang terlibat dalam kegiatan ini

\section{DAFTAR PUSTAKA}

Anita Dewi W, Anjarwati S. Pengaruh Penyuluhan tentang Kanker Serviks dengan metode peer group terhadap minat ibu Melakukan pap smear di desa Caturharjo Sleman tahun 2013.

Elleson LH. Pirog EC. The Female Genital Tract Chapter 22. In Robinns and Cotran Pathologic Basis of Desease. $8^{\text {th }}$ Eds. Editor Kumar Abbas Fausto Aster. Philadelphia. Saunders Elsevier 2010. P. 1017-24

Fauziah, Ratri Manjari. 2011. Deteksi Dini Kanker Serviks pada Pusat Pelayanan Primer di Lima Wilayah DKI Jakarta. Jakarta: Artikel Kesehatan Vol. 61. No. 11. Hal. 447-453

Globocan/ IARC. 2012. Estimated Cancer Incidence, Mortality and Prevalence Worldwide in 2012. http://globocan.iarc.fr/default.aspx

Gondo Mastutik et al: Skrining Kanker Serviks dengan pemeriksaan pap smear di Puskesmas Tanah Kali Kedinding Surabaya dan Rumah sakit Mojokerto.Majalah Obstetri Dan Ginekologi Vol.23 No.2 tahun 2015 54-60

I Gede Putu Darma S. Made Risnawan. Penyuluhan Kanker Serviks pada Wanita Masa Reproduksi di Desa Nyuh Tebel Kecamatan Manggis. Kabupaten Karangasem. Jurnal Paradharma 1 (2). 62-67. ISSN: 2549-7405 tahun 2017

Maharani, Sabrina. 2009. Mengenal 13 Jenis Kanker Dan Pengobatannya. Jogjakarta: Katahati

Rasjidi 2009. Deteksi dini dan Pencegahan Kanker Servik pada Wanita. Jakarta. Sagung Seto.

Rohmawati, Ika. 2011. Faktor yang Berhubungan dengan PUS dalam Deteksi Dini Kanker Serviks dengan IVA di Wilayah Kerja Puskesmas Ngawen I Kabupaten Gunung Kidul.Skripsi. Jakarta: FKM UI

Suarniti, Ni Wayan. 2013. Pengetahuan Dan Motivasi Wanita Pasangan Usia Subur Tentang Tes Inspeksi Visual Asam Asetat Di Propinsi Bali Indonesia. Bali. Artikel Ilmiah. Vol.24. No.2. Hal. 125-140 